Medicine Updates

Faculty of medicine

April 2020,volume 1, issue 1 https://muj.journals.ekb.eg dean@med.psu.edu.eg vice_dean_postgraduate@med.psu.edu.eg

DOI: $10.21608 / \mathrm{muj} .2020 .25068 .1001$

ISSN : 2682-2741

Submitted: $25 / 1 / 2020$

Accepted : 13/3/2020

Pages:68-71

\title{
MRI of male breast carcinoma
}

Carmen ali ahmed, lecturer of radiodiagnosis faculty of Medicine port said Universty Egypt.

\section{$\underline{\text { Abstract }}$}

MRI breast is designed to diagnose breast cancer in female. MRI has a great role in diagnosis of early breast cancer. MRI has a great role in differentiation between postoperative scar and post-operative recurrence in cases of surgically removed cancer breast. MRI also used in follows up the response of chemotherapy in cases of advanced breast cancer. Few literatures explain the use of MRI in male breast cancer. In this case report we present a case of male breast cancer and demonstrate MRI characters, enhancement and diffusion patterns similar to that occur in female breast cancer. In our case report we concluded that MRI morphologic features of cancer breast in male were the same MRI morphologic features of cancer breast in female. Cancer breast in male showed the same enhancement kinetic similar to that occurred in female with cancer breast. Cancer breast in male showed a similar enhancement curves like that in female with breast cancer. Cancer breast in male has the same diffusion patterns that occur in female with cancer breast.

Abbreviations: $\mathrm{MRI}$, magnetic resonance imaging 


\section{Case report:}

Male patient aged 48 years presented by palpable lump in the right breast axillary tail

Contrast-enhanced magnetic resonance imaging performed to the patient. Dynamic post-contrast T1 subtraction image (figure 1) showed irregular shaped mass in the axillary tail of the right breast. The mass was irregular shape with homogenous enhancement. The mass showed type 3 (washout) dynamic curve (figure 2). In diffusion weighted image (figure 3) the mass was high signal intensity denoting restricted diffusion with low ADC value 0.81 $\times 10^{-3} \mathrm{~mm}^{2} / \mathrm{sec}$ in ADC map (figure 4). This mass was categorized as BI-RADS 5 Core biopsy revealed a grade III, invasive ductal carcinoma.

\section{Discussion}

Breast cancer in male is rare. Male breast cancer occurs in only $1 \%$ of all breast cancers $(1,2)$

In the past mammography was used for early diagnosis of breast cancer in male, the mammographic features of cancer breast in male were similar to those found in breast cancer in female (3).

The most important imaging modality for diagnosis of cancer breast in male is Ultrasound. Ultrasound has a great role in evaluation of male breast cancer; it also shows the same features like those seen in the female with breast cancer (3).

In our case report we concluded that MRI morphologic features of cancer breast in male were the same MRI morphologic features of cancer breast in female. Cancer breast in male showed the same enhancement kinetic similar to that occurred in female with cancer breast. Cancer breast in male showed a similar enhancement curves like that in female with breast cancer. Cancer breast in male has the same diffusion patterns that occur in female with cancer breast. 

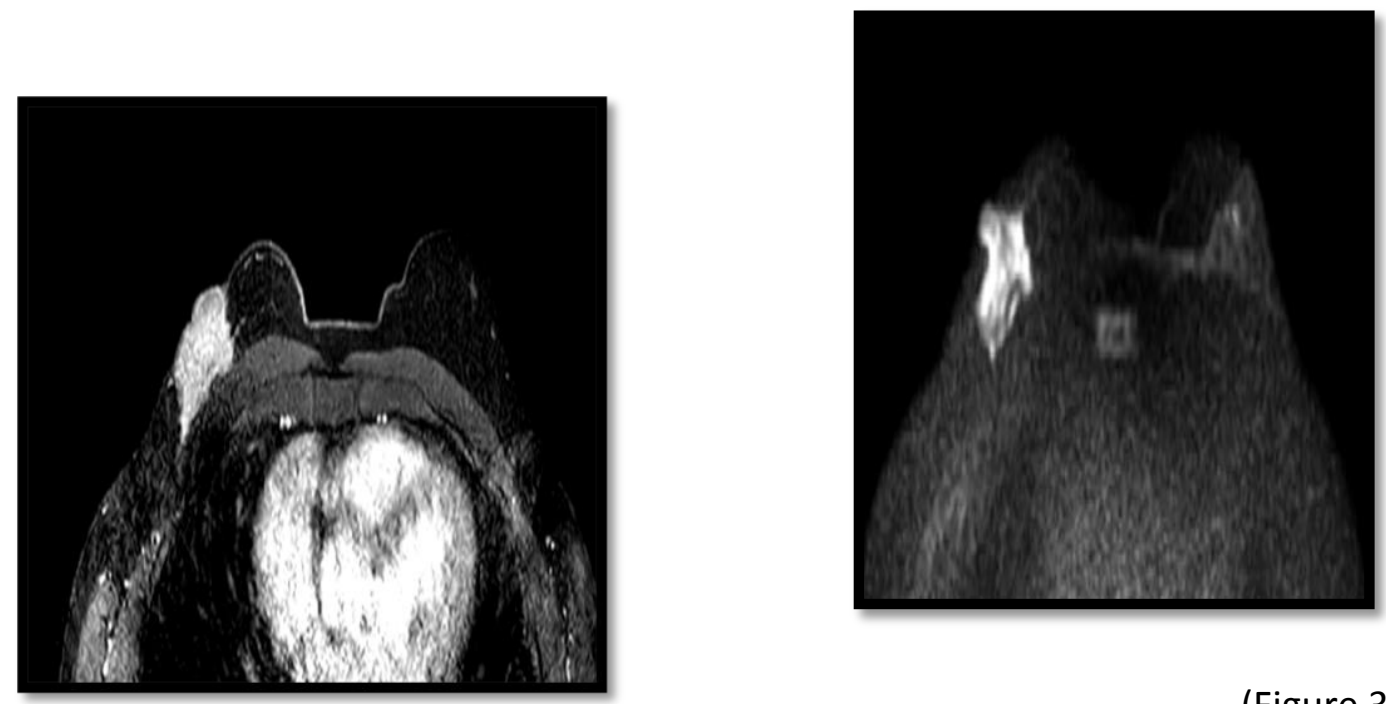

(Figure 3)

(Figure 1)
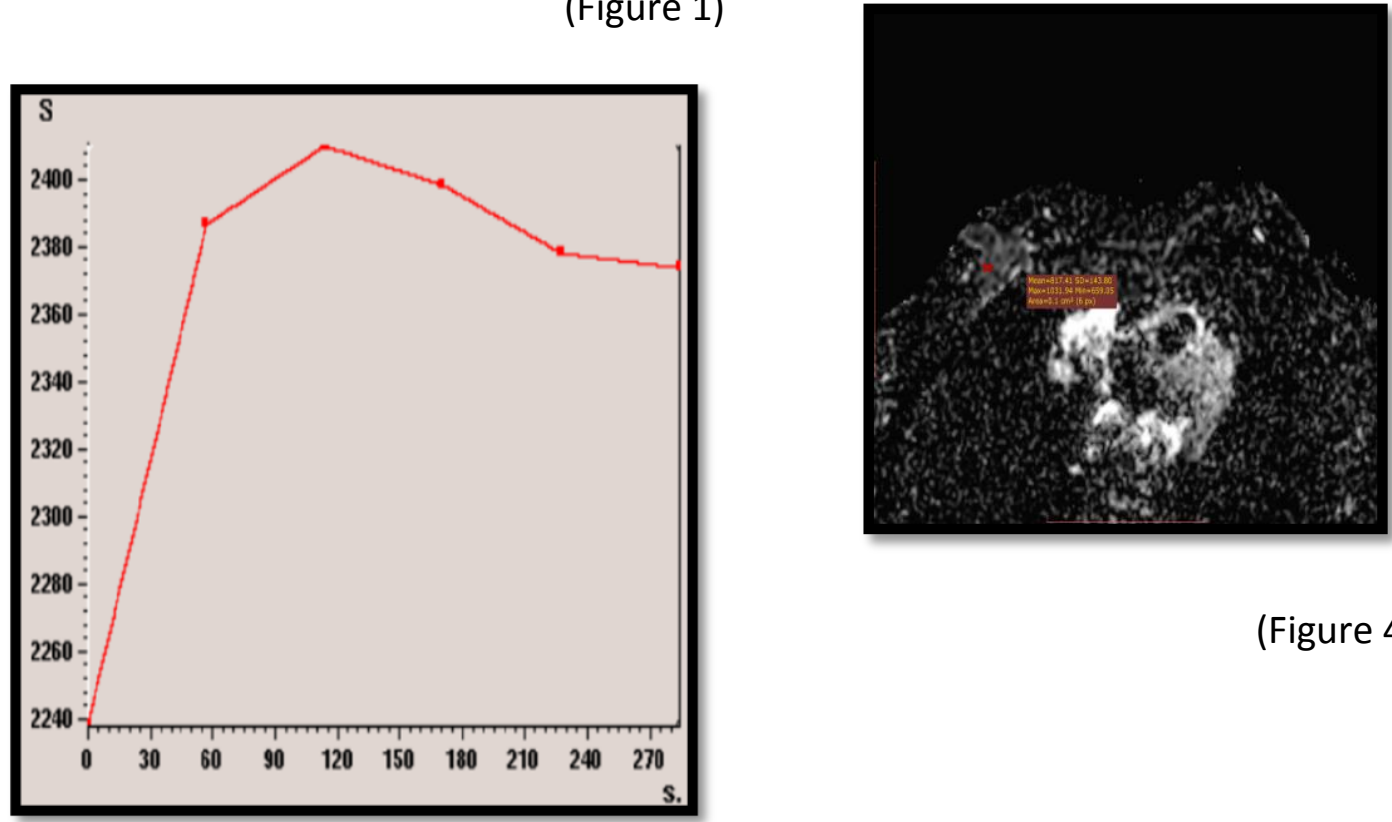

(Figure 4)

(Figure 2) 


\section{$\underline{\underline{\text { References }}}$}

1. Landis SH, Murray T, Bolden S, Wingo PA. Cancer statistics, 1999. CA Cancer J Clin. 1999;49:8.

2. Weiss JR, Moysich KB, Swede H. Epidemiology of male breast cancer. Cancer Epidemiol Biomarkers Prev. 2005;14(1):20-26.

3. Shaw A, Smith B, Howlett D. Male breast carcinoma and the use of MRI. 2011: Radiology Case Rep. 2011; 6(3): 455. 